\title{
Silver shield: a local government's approach to critical infrastructure protection
}

\author{
S. Conway, P. Washeba, R. Thomas \& R. Cameron \\ Urban Environmental Research, LLC, USA
}

\begin{abstract}
Silver Shield serves as Nevada's central repository for critical asset data and aligns closely with the United States Department of Homeland Security's Infrastructure data warehouse. Silver Shield's mission is to identify, catalogue, prioritize, and coordinate the protection of critical infrastructure and key resources to support Federal, State, local, and tribal readiness, prevention, mitigation, and response efforts. Critical Infrastructure include both public and private sector systems and assets, whether physical or virtual, that are so vital that their incapacity or destruction will have a debilitating effect on the security, economy, public health or safety, environment, or any combination of these matters across any Federal, State, regional, territorial or local jurisdictions. This paper discusses how the Southern Nevada Counter Terrorism Center, Northern Nevada Counter Terrorism Center, and the Nevada Threat Assessment Center have come together to meet this challenge.
\end{abstract}

Keywords: critical infrastructure protection.

\section{Introduction}

Silver Shield is the focal point for a statewide unified approach to critical infrastructure and key resources (CIKR) identification, cataloguing risk determination, mitigation planning, and exercising preparedness across all areas of Nevada. Critical Infrastructure include both public and private sector systems and assets, whether physical or virtual, that are so vital that their incapacity or destruction would have a debilitating effect on the security, economy, public health or safety, environment, or any combination of these matters across any Federal, State, regional, territorial or local jurisdictions (U.S. National Infrastructure Protection Plan, 2009).

Critical infrastructure protection is outlined as one the top priorities of the U.S. Department of Homeland Security via the Homeland Security Presidential 
Directive 7 (HSPD-7). Implementing the Nevada Infrastructure Protection Program (NIPP) aligns closely with the United States Department of Homeland Security's effort to enhance public safety through infrastructure protection. Program responsibilities include the development, implementation, and continuous review of a risk management plan to identify, capture, and assess locations of interest in relation to public safety (U.S. National Infrastructure Protection Plan, 2009). To do so, Silver Shield facilitates appropriate information sharing with its public safety partners on CIKR information, thus supporting the state \& local jurisdiction plans for protection and restoration of CIKR services, facilities, utilities and other processes. Silver Shield not only aligns with national priorities and plans such as the NIPP, but also the National Preparedness Goals Target Capabilities List with state and local priorities and plans, the Nevada State Homeland Security Strategy and Capability Enhancement Plan. Silver Shield is able to do this primarily via its main goal and objective of developing a statewide network for the collection, analysis and sharing of critical infrastructure information in partnership with state, local, and tribal, and private sector organizations (Nevada State Homeland Security Strategy, 2007; Las Vegas Urban Area Security Strategy, 2008). Concurrently, Silver Shield supports Federal, State, local, and tribal readiness, prevention, mitigation, and response efforts within the fusion center process. This methodology brings representatives from across the spectrum of affected intrastate agencies into a single facility to enhance their efforts to gather, process, analyze and disseminate terrorism information, homeland security information and law enforcement information.

Nevada's three fusion centers work together to implement the National Infrastructure Protection Plan and aspects pertaining to its goals. The fusion centers include the Nevada Threat Assessment Center (NTAC) in Carson City, the Northern Nevada Counter Terrorism Center (NNCTC) located in Reno, and the Southern Nevada Counter Terrorism Center (SNCTC) in Las Vegas. The Washoe County Sheriff's Office supports the location for the Northern Nevada Counter Terrorism Center, which houses the Northern hub of the Silver Shield Program. The Las Vegas Metropolitan Police Department (LVMPD) provides the project management and administrative support for the statewide Silver Shield program and the Southern Nevada Counter Terrorism Center, and houses the Southern hub of the Silver Shield Program. The rural counties are supported by the Nevada Threat Assessment Center (NTAC). The fusion centers house various local, state, and federal agency representatives and strive to improve public health and safety through a joint effort related to counter terrorism. Further, the fusion centers put great importance on critical infrastructure protection through the Silver Shield Program.

\section{Current capabilities}

\subsection{First responder tool}

Silver Shield provides the tool to collect and archive critical infrastructure data, and the means to disseminate that information via a web-based first responding 
agency tool. The first responder tool is a mechanism by which fire, police, and emergency management may obtain critical information in the event of an incident. Further, this tool provides full integration of the geospatial/geographic information system (GIS) software that provides a predictive analytical component that creates increased capability for domestic intelligence and law enforcement in combating terrorism, gangs, and conventional criminal activity, in a preventive and proactive sense. Full integration will provide similar capabilities in the event of natural disasters. The continuing development of a system in which to collect, store, and distribute critical infrastructure and key resources data improves vital protection capabilities. The information required for the first responder tool was established by conducting "common operating picture" meetings. These meetings consisted of a discussion among representatives from fire, police, and emergency management agencies pertaining to what information would be useful and necessary when responding to an emergency. Silver Shield collects the information deemed to be important in the "common operating picture" meetings during the Phased Site Assessments.

\subsection{Phased site assessment}

The critical infrastructure information from the "common operating picture" meetings includes floor plans, key site contacts, staging areas, utility shut-offs, aerial photographs, tactical pre-plans, hazardous materials locations and proximity, and other site characterization information. In order to obtain this information and populate it into the first responder tool, the Silver Shield team participates in several tasks. Emergency response plans are garnered by guiding and assisting public/private sector owner/operators in formulating their plans. Further, floor plans, photographs, and other key information are collected during the vital task of site assessments. Currently, Silver Shield participates in three types of site assessments: Phase I, Phase II, and Phase III. Phase I Site Assessments are based on the controlled implementation approach to Critical Infrastructure protection developed by DHS, and promulgated through the Critical Asset/Key Resource Asset Protection Technical Assistance Program (CAPTAP). This consists of making initial contact with the owners/operators or designees of those facilities, systems or assets which are representative of the area's critical infrastructure, mass population centers or sites having symbolic importance. The Silver Shield team completes a base level of initial survey activities and populates the Constellation/Automated Critical Asset Management System (C/ACAMS) and the emergency management tools as developed for first responders as appropriate with that information. Each site assessment takes approximately 40 man hours to complete. Phase II Site Visits are based on the next phased approach to Critical Infrastructure protection developed by DHS, and are also promulgated through the Critical Asset/Key Resource Asset Protection Technical Assistance Program (CAPTAP). Phase II is a more comprehensive risk analysis (the Initial Asset Visit in the C/ACAMS system) which develops preventive plans, proposed security enhancements, and uses the Mission, Symbolism, History, Accessibility, Recognizability, Recoverability, 
Population, Proximity, Vulnerability (MSHARRPP+V) risk analysis and associated reports. Phase III goes on to develop post event plans and more extensive "all-hazards" approaches to risk reduction. Support for this task will include preparing all progress reports as required by DHS, the State of Nevada, and responding to all data calls.

\subsection{Training}

Silver Shield also compiles, organizes, and catalogs data from other sources in addition to the phased site assessments including C/ACAMS, police departments, fire departments, and web-based sources. In order to use this information effectively, Silver Shield conducts training activities on a regular basis. Critical Infrastructure Analysts are trained to identify, catalogue, and collect critical infrastructure and key resources data, while Infrastructure Liaison Officers (ILO) are trained as the coordinating point for private sector organizations on issues related to terrorism. The ILO duties consist of acting as an interagency representative, in-house subject matter expert, and terrorism intelligence analyst (KIPP, 2009). These training courses and the first responder tool are used in the stakeholder outreach plan to coordinate and educate about critical infrastructure protection on a statewide level. Training not only facilitates usage of the first responder tool, but has the additional ability to improve the capability to identify, catalogue, and collect critical infrastructure and key resources data.

\subsection{Special events}

Silver Shield also provides support for special events including NASCAR races and New Year's Eve celebrations for the Las Vegas Metropolitan Police Department and other public safety agencies. These two example events have amassed crowds of 150,000 and 350,000 attendees respectively. Assistance includes personnel, hardware, and mapping support which improves the prioritization and measurement of effectiveness capabilities. The personnel consist of geographic information systems (GIS) scientists and critical infrastructure analysts. Their main function is to provide the Panasonic Toughbook laptop hardware with first responder tool with mapping capabilities. This assistance lends itself to increased functioning during events when mass population safety is a concern.

\subsection{DHS data call}

The data call is a process in which CIKR is identified, assessed and incorporated into the appropriate category and submitted through the Linked Encrypted Networking System (LENS) portal. Assessment includes a detailed evaluation of each asset as it relates to infrastructure protection. Further, a DHS approved state plan to respond to such activities and corresponding prioritization of DHS sectors and sector leads gives statewide standardization which increased protection capabilities. 


\section{Future implementation}

Silver Shield will complete several tasks to properly implement the critical infrastructure protection program. Silver Shield will continue the implementation of phased site assessment visits to identify, capture, store, and catalogue the state's critical infrastructure and key resources across the public/private sectors. Further, Silver Shield will continue to populate critical infrastructure information in the C/ACAMS and in the first responder tool. Also, Silver Shield will continue to respond to the DHS data call each year and populate LENS. Future implementation will also include the first responder tool, training, and special events assistance.

\subsection{First responder tool}

The northern and southern hubs of the Silver Shield Program will exercise and test all equipment and software to ensure proper and effective deployment of the first responding agency tool throughout the state. The critical infrastructure protection program provides a central repository for CIKR information in an interactive web-based portal. Full integration of the geospatial/GIS software will provide a predictive analytical component for domestic intelligence and law enforcement in combating criminal activity in a preventive and proactive sense. In addition, by enhancing the critical infrastructure repository to include floor plans, key site contacts, staging areas, utility shut-offs, aerial photographs, tactical pre-plans, and hazardous materials the Fusion Centers, Emergency Operations Centers, and other first responders will have a web-based tool with critical information. This tool will help to reduce risks to first responders and support the development of specific protective programs for CIKR of the highest criticality based on risk. Silver Shield will be responsible for continuing to update, enhance, and refine this statewide web-based program. Future implementation of the first responder tool will include enhanced crime analysis, mapping capabilities, and rapid consequence management.

\subsection{Training}

Silver Shield will continue training programs. Sector specific ILO training will be developed. Three training courses will be established for the transportation systems sector, selected segments of the commercial facilities sector, and major utilities sectors. Further, these ILO training courses will be conducted quarterly across the State of Nevada. In addition, statewide interdependency meetings will be conducted annually to include all 18 sectors. These meetings will contribute to the state's security by providing an opportunity to identify interdependencies and develop cohesive strategies for prioritizing and mitigating risks. Finally, Silver Shield will develop and maintain a systematic training program for critical infrastructure analysts to continue to refine and enhance subject matter expertise in key sectors. This will include quarterly reporting on capabilities and gaps. 


\subsection{Special events}

Silver Shield will continue to support and refine event planning capabilities through participation in tabletop, functional, and full scale exercises with the Las Vegas Metropolitan Police Department (LVMPD) and other public safety agencies throughout the state. This includes deployment of geospatial tools for use by first responders. Further, the task will include organizing participants, reviewing existing plans, conducting the exercises, and producing an after-action report with observations. In addition, Silver Shield will participate in the 2010 National Level Exercise (NLE 2010) sponsored by DHS.

\section{Sustainability}

The continued need for staffing, software/server support, equipment maintenance and upgrades, plus the associated operating costs, will persist. Whenever possible, efforts are being made to leverage existing IT infrastructure and technical support. Funding for those needs will be arranged by the managing entity, and governance will be dictated in accordance with state statute, local ordinances and contract language enforced by the Attorney General and District Attorneys.

The Homeland Security Commission is establishing a subcommittee comprised of multiple agencies from the first responder community and members of the private sector, who will be tasked with providing oversight to the program and to oversee the development and deployment of a long-term sustained funding mechanism that will likely include funding from state and local governments, additional grant monies, and/or endowments from various public/private sector sources may also be used. Bringing the sectors together on the Commission is designed to gain acceptance across the private and public sector so that over time ownership becomes shared. This sharing enhances planning efforts, utilization of the data and vulnerability analysis, and simultaneously increases the probability of support from participating members. Hence, as the various sectors become more involved in the functions of Silver Shield, become aware of the advantages of participation, training, and information and intelligence access, support for Silver Shield and willingness to share costs will increase.

\section{Conclusion}

By continuing to identify, catalogue and assess vital information across Nevada, risks are reduced relating to critical infrastructure at the federal, state, and local level fulfilling the primary target capability. For example, at the federal level this activity supports the development of the national risk profile as outlined in the National CIKR Protection Annual Report. The national risk profile is a highlevel summary of aggregate risk and protective status across all sectors. At the state and local level, the cataloguing and assessing of risks provides decision makers with vital information for prioritizing resources and developing risk 
mitigation strategies fulfilling a secondary target capability of risk management. In addition, by enhancing the critical infrastructure repository to include floor plans, key site contacts, staging areas, utility shut-offs, geo-tagged aerial photographs, tactical pre-plans, and other site characterization information, to include hazardous materials locations in proximity to the affected infrastructure sites, the Fusion Centers, Emergency Operations Centers, and other first responders will have a web-based tool containing critical information that reduces risks to first responders and supports the development of specific protective programs for $\mathrm{CI} / \mathrm{KR}$ of the highest criticality based on risk. This outcome supports two target capabilities to include information gathering and recognition of indicators and warnings; and intelligence information sharing and dissemination.

Integration of the program's existing software platform with data dissemination technology will provide a robust, encrypted capacity to deliver critical response data, whenever, wherever, and to whomever requires it. The precise nature, severity, and dynamics of the disaster environment can be communicated in a timely fashion, further minimizing the potential for escalation. Silver Shield complements other plans designed to help prevent, prepare for, protect against, respond to, and recover from terrorist attacks, natural disasters, and other emergencies. Additionally, private sector owners and operators of critical infrastructure assets are encouraged to utilize Silver Shield when developing their business continuity and resilience measures.

Successful completion of this project will strengthen Information Gathering and Recognition of Indicators and Warning, Intelligence Analysis and Production, Counter-Terror Investigation and Law Enforcement, Infrastructure Protection, and Intelligence and Information Sharing and Dissemination both within the three Nevada fusion centers, and across all public safety agencies. The Southern Nevada Counter Terrorism Center, Northern Nevada Counter Terrorism Center, and the Nevada Threat Assessment Center work together to help implement Nevada's critical infrastructure protection plan and save the lives of first responders to an incident.

\section{References}

[1] Department of Homeland Security (2009). National Infrastructure Protection Plan.

[2] Knowledge and Intelligence Program Professionals (KIPP). Homeland Security: Community Information Networking (March, 2009), www.kippintelligence.com/homelandsecurity.html.

[3] Local Emergency Planning Committee (2008). Las Vegas Urban Area Security Goals.

[4] Nevada State Homeland Security Commission (2007). State Homeland Security Strategy. 